\title{
Application of Proteus in the Teaching of Computer Control Technology
}

\author{
Hongqian $\mathrm{Lu}^{1, \mathrm{a}}$, Chunmei Duan ${ }^{2, \mathrm{~b}}$ * \\ ${ }^{1}$ School of Electrical Engineering and Automation, Qilu University of Technology, Jinan,China \\ ${ }^{2}$ School of Management Science and Technology, Shandong Normal University, Jinan, China \\ ahqlu@qlu.edu.cn, bchunmeiduan@mail.sdu.edu.cn
}

Keywords: Proteus; Teaching; Computer Control

Abstract. Computer Control Technology is an important course for university students of electrical engineering and automation major. This paper analyzes the problems in traditional way of teaching by introducing Proteus simulation software in teaching. We analysis in detail the application of Proteus in teaching through a teaching examples. We believe that software simulation of teaching examples will improve the overall design capabilities of computer control system of students.

\section{Introduction}

Computer Control Technology is a comprehensive and important technical course for university students in school of electrical engineering and automation. The course requires students to master control theory, computer control system analysis and design methods, and basic design skills to design a simple computer control system [1].

In the process of teaching the course, we find that students usually feel difficult in computer control system hardware design, which is abstract and difficult to image. Usually, in teaching practice, teachers first explain the theory and use theory to explain the relevant practical part, which makes the theory and practice teaching disjointed.

Computer control system test box is used in experimental process of Computer Control Technology, whose internal structure is fixed. So, students only do some simple connection during experimental process, and then check and analyze the results system operation. Such experiments are unable to practice the abilities of students to design a computer control system. Obviously, current laboratory hardware are unable to meet existing experimental modern teaching needs.

Fortunately, with the development of computer technology, simulation technology has become an important mean to aid circuit analysis and system design. Particularly, Proteus simulation software from UK Labcenter Electronics Company, combines circuit simulation, PCB design and simulation of a virtual model together effectively to solve the problem of the design and co-simulation of microcontroller and peripheral circuits [2]. Many teachers have employed Proteus in relevant teaching [3-5]. In this paper, we analysis in detail the application of Proteus in teaching through a teaching examples. We believe that software simulation of teaching examples will improve the overall design capabilities of computer control system of students.

\section{Application of Proteus in Computer Control Technology Teaching}

Proteus is an EDA tool which can simulate microcontroller and peripheral devices. Proteus can truly turn a complete design from concept into product. Proteus can program based on the virtual prototype directly. Together with display and output devices, input and output can be seen after running of programs. Proteus establishes a comprehensive electronic design and development environment.

Teaching content of Computer Control Technology course includes theoretical teaching and experimental teaching, which are mainly related to hardware design techniques such as bus technology, analog and digital input and output, digital control technology, practices and complex control technology, computer control system design and implementation. Previous form of teaching is explain the experiment in theory firstly and then partially validate the analysis, which will result in

\footnotetext{
${ }^{*}$ Corresponding author
} 
a disjointed process of theory and practice. Especially in teaching knowledge such as hardware I / O addressing, A / D and D $\backslash \mathrm{A}$ transformation, stepper motor control about the parallel interface chip 8255A, timer counter chip 8253, 8259, and interrupt controller chip. These chips work more complicated due to too many pins and complicated links. Consequently, it is difficult for students to understand and grasp a lot of related knowledge.

Now, after the introduction of Proteus software, we can directly show real-time running effects of these circuit chips, meanwhile dynamically change the parameters related to devices just in the classroom, which shows the advantages combination of virtual simulation and the theory. Therefore, using Proteus in classroom can demonstrated corresponding examples to explain the theory of knowledge, which can greatly improve learning initiative of student. On the other hand, Proteus updates soon, so the latest relevant teaching device can be found in the new version of Proteus. Doing simulation laboratory experiments using Proteus can help students to solve the problems concerned with fixed experimental device structure, so that students can quickly grasp the relevant skills and learn about the latest computer-controlled technology.

Especially, some practices has proved that the introduction of Proteus into class teaching of Computer Control Technology can make teaching process be intuitive, effective. Besides, teaching content can keep up with the improvement of the current technology which can inspire students to keep up with current technology.

\section{Proteus simulation example}

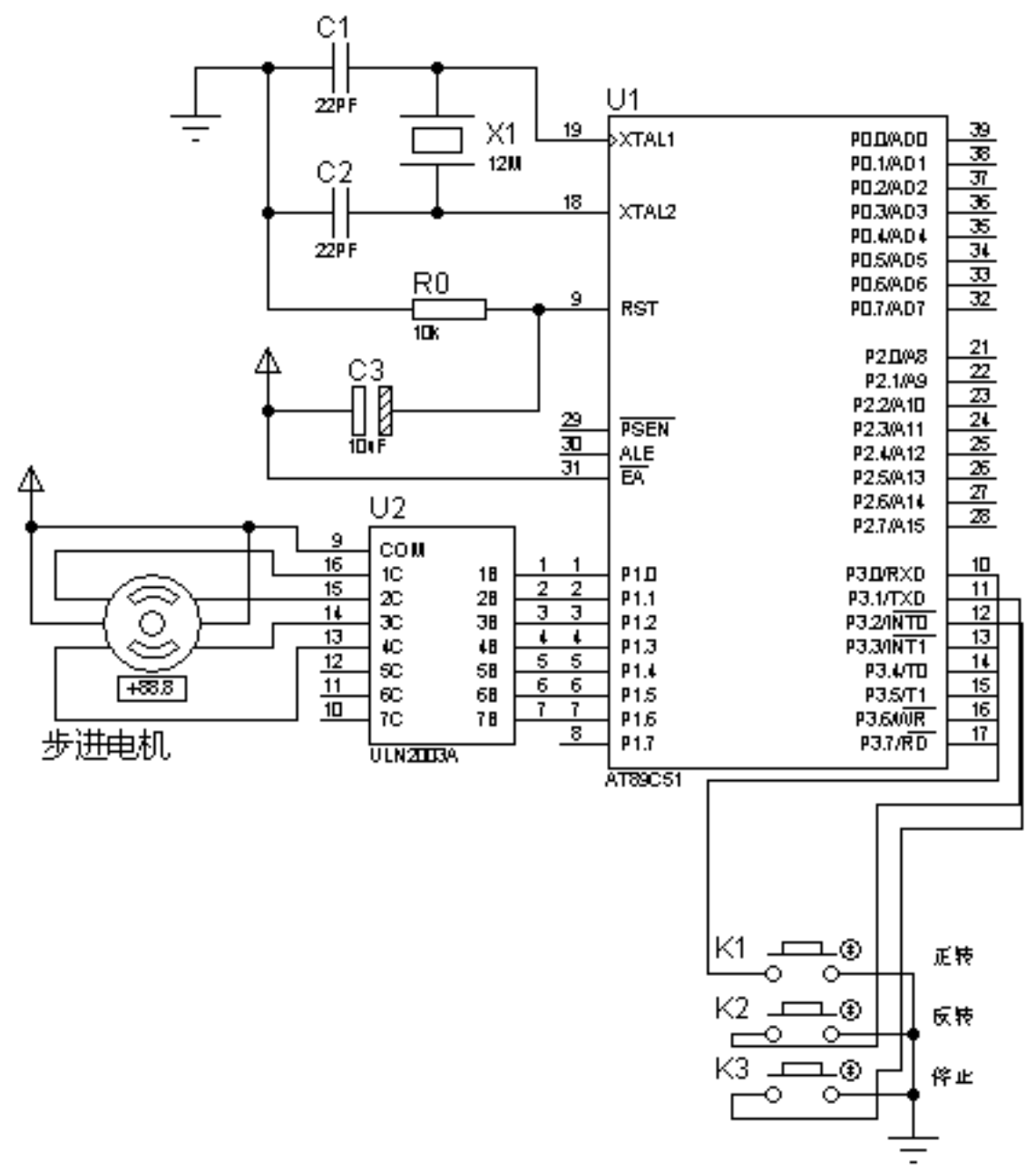

Fig.1 Stepper motor circuit schematics

In this paper, we describe the process using Proteus for virtual simulation in the teaching of computer control technology based on AT89C51 stepper motor control. This example mainly 
contains four steps as key input, interrupts, timers, stepper motor. After the system is running, we can use buttons to start, stop, forward and reverse the stepper motor. From this example, students can be very intuitive to see the process of hardware design, software programming and debugging, and the running states of the stepper motor. By this example, students can take deep understanding of the work mechanism of the stepper motor and some ways to operate hardware. Further, during the process of simulation using Proteus, students can always modify the parameters related to the device, or to replace certain parts, which can greatly improves the students' enthusiasm for learning. Meanwhile, the most important thing is that it is very easy for students to master the software and hardware design methods of stepper motor control system through usage of Proteus.

In this example, as shown in figure 1, we adopt Proteus 7.8 sp2 together with Keil C51 to perform the simulation, Firstly, start the Proteus 7.8 and add the required components as shown in Figure 1, and then connect the circuit diagram in accordance with the need. Secondly, to complete the design of the program in the Keil software. Then, complete the flowchart of the program as shown in figure 1 and code with the popular $\mathrm{C}$ programming language, then generate the corresponding HEX object file by Keil software. Double-click the AT89C51 in the Proteus and load the HEX object file generated by Keil software, run the simulation program, click on the appropriate button, and you can control the running direction of the stepper motor.

\section{Summary}

Computer Control Technology course are of strong theoretical and practical feature. To introduce Proteus to class teaching will promote teaching and learning effectiveness and improve the capabilities of students to carry out computer control system design, analysis. In this paper, we prove that Proteus can reduce the investment of laboratory economic and keep teachers and students up with the development of today's computer control technology. However, Proteus simulation program can simulate the hardware design, but cannot completely replace the hardware design. Therefore, students must really implement some physical part using Proteus simulation diagram to do further verification in order to truly improve the computer control system design capabilities.

\section{Acknowledgements}

This paper was supported by Project of Shandong Province Higher Educational Science and Technology Program (J13LN14) and Teaching Reform Project of Shandong Normal University (2012) and Natural Science Foundation of Shandong Province of China(ZR2013FM022) and Teaching Reform Project of Qilu University of Technology (2013).

\section{References}

[1]H.S, Yu: Computer control technology, (CMP) China Machine Press, 2011.

[2]H. Yue: Application of project teaching method and Proteus simulation in SCM Teaching, Occupation technology education, Vol 35(2011), pp55.

[3]L. Chen, Y.J. Zhang: Application of Proteus in MCU experiment teaching, Experimental Technology and Management, Vol. 26 (2009), pp73

[4]Y. Chen, H. Gu, .Y. Liang: Application of Proteus virtual simulation in the teaching of Microcomputer Principle, Technology and application of computer, Vol. 38(1),2012,pp.106-108.

[5] J.H. Qiao, L.S. Li , Q.H. Tian, Application of Proteus in MCU Teaching, Electrical \& Electronic Engineering Education, 2008,30(3),pp.70-73. 